Int. J. Electrochem. Sci., 13 (2018) $4309-4318$

\title{
Electrocatalytic Determination of L-cysteine in the Presence of Tryptophan Using Carbon Paste Electrode Modified with MgO Nanoparticles and Acetylferrocene
}

\author{
Vinod Kumar Gupta, ${ }^{1, *}$, Zahra Shamsadin-Azad ${ }^{2}$, Somaye Cheraghi ${ }^{2,3}$, Shilpi Agarwai, \\ Mohammad A. Taher ${ }^{2, *}$ Fatemeh Karimi \\ ${ }^{1}$ Department of Applied Chemistry, University of Johannesburg, Johannesburg, South Africa \\ ${ }^{2}$ Department of Chemistry, Mashhad Branch, Islamic Azad University, Mashhad, Iran \\ ${ }^{3}$ Department of Chemistry, Graduate University of Advanced Technology, Kerman, Iran \\ ${ }^{4}$ Department of Chemical Engineering, Laboratory of Nanotechnology, Quchan University of \\ Technology, Quchan, Iran \\ *E-mail: vinodfcy@gmail.com; ma-taher@uk.ac.ir
}

doi: $10.20964 / 2018.05 .53$

Received: 27 January 2018 / Accepted: 10 March 2018 / Published: 10 April 2018

The electrical conductivity effect of $\mathrm{MgO}$ nanoparticle (MgO-NPs) and electro-catalytic effect of acetylferrocene (AF) was studied for modification of carbon paste electrode (CPE) as a highly sensitive electrochemical sensor for electro-catalytic determination of L-cysteine in the aqueous solution. The $\mathrm{AF} / \mathrm{MgO}-\mathrm{NPs} / \mathrm{CPE}$ showed good electro-catalytic activity for analysis of L-cysteine in the concentration range $0.1-700.0 \mu \mathrm{M}$ with limit of detection $30.0 \mathrm{nM}$ using differential pulse voltammetric method (DPV). In addition, the AF/MgO-NPs/CPE showed two separated oxidation signals with $\Delta \mathrm{E} \sim 170 \mathrm{mV}$ in the solution containing L-cysteine and tryptophan that is sufficient for simulations determination of these amino acids with same oxidation potential at a surface of unmodified electrode.

Keywords: Acetylferrocene; $\mathrm{MgO}$ nanoparticle; L-cysteine, Tryptophan, Electrocatalysis

\section{$\underline{\text { FULL TEXT }}$}

(C) 2018 The Authors. Published by ESG (www.electrochemsci.org). This article is an open access article distributed under the terms and conditions of the Creative Commons Attribution license (http://creativecommons.org/licenses/by/4.0/). 